\title{
TABEL VOLUME BATANG DI BAWAH PANGKAL TAJUK JENIS TENGKAWANG (Shorea macrophylla) DI PT GUNUNG GAJAH ABADI, KALIMANTAN TIMUR \\ (Clearbole Volume Table for Tengkawang (Shorea macrophylla) in PT Gunung Gajah Abadi, East Kalimantan)
}

\author{
$\mathrm{Oleh} / \mathrm{By}$ : \\ Abdurachman ${ }^{1)}$ dan Sri Purwaningsih ${ }^{2)}$ \\ ${ }^{1}$ Balai Besar Penelitian Dipterokarpa, Samarinda \\ ${ }^{2}$ Balai Penelitian Teknologi Agroforestry Ciamis
}

\begin{abstract}
Clearbole Volume Table for tengkawang (Shorea macrophylla) at makes to help encrease estimate of volume of that species. It was based on 51 selected sample trees taken from the field. Five regression equation were used ti develop model based on diameter. The best model based on determinant coefficient $\left(R^{2}\right)$, agregatif deviation (SA) and average deviation (SR). the result showed that the regression equations were use for of volume were $\log V=-3.3545+2.2249 \log d-3.9328$ (1/d) with standard error 0.1162, determinant coefficient $\left(R^{2}\right)$ 0.9727, agregatif deviation (SA) $-1.54 \%$ and average deviation (SR) $3.26 \%$.
\end{abstract}

Key Words : Diameter, volume table, tengkawang (Shorea macrophylla).

\begin{abstract}
ABSTRAK
Tabel volume batang jenis tengkawang (Shorea macrophylla) dibuat untuk membantu meningkatkan taksiran dari volume dari jenis tersebut. Sebanyak 51 sampel pohon model diambil dari areal penelitian. Penyusunan model regresi terdiri dari 5 persamaan dengan berdasar pada peubah bebas diameter. Pemilihan model terbaik berdasarkan koefisien determinasi $\left(\mathrm{R}^{2}\right)$, simpangan agregat (SA) dan simpangan rata-rata (SR). Hasil penelitian menunjukkan bahwa model persamaan yang digunakan adalah $\log \mathrm{V}=-3.3545+2,2249 \log \mathrm{d}-3,9328$ (1/d) dengan kesalahan baku 0,1162, koefisien determinasi $\left(\mathrm{R}^{2}\right)$ 0,9727, simpangan agregatif -1,54\% dan simpangan rataan (SR) 3,26\%.
\end{abstract}

Kata Kunci : Diameter, tabel volume, tengkawang (Shorea macrophylla). 


\section{PENDAHULUAN}

Perangkat penduga volume pohon yang mempunyai ketelitian yang tinggi diperlukan dalam rangka memperoleh penaksiran potensi suatu tegakan. Hal ini diperlukan untuk perencanaan hutan setelah pelaksanaan inventarisasi dengan data yang akurat. Akinnifesi (1995) menyatakan penggunaan teknik yang tepat, handal dan up to date dalam pendugaan yang benar untuk volume pohon kayu berguna dalam efisiensi pengelolaan potensi tegakan. Tabel volume lokal (tarif) akan sangat membantu pengelolaan hutan setempat didalam penyusunan rencana dan pengaturan hasil hutan.

Pendugaan volume dengan menggunakan angka bentuk batang dalam penaksiran potensi tegakan akan memberikan perbedaan nilai yang besar dari kondisi yang sebenarnya. Bambang dan Wahyono (1996) menyatakan penaksiran dengan cara menggunakan angka bentuk batang yang umum diguna- kan sebesar 0,7 diduga merupakan salah satu sumber kesalahan dalam penaksiran sehingga dapat mengakibatkan perbedaan yang cukup besar antara angka taksiran dengan angka sebenarnya.

Berdasarkan hal diatas, maka tujuan dari penyusunan tabel ini adalah untuk meningkatkan ketelitian dan keseksamaan dari hasil inventarisasi massa tegakan dari jenis pohon yang bersangkutan, dengan harapan berguna dalam kegiatan timber cruising di lapangan dalam rangka menyusun rencana-rencana pengelolaan hutan pada daerah tersebut.

\section{RISALAH JENIS}

Tengkawang buah (Shorea macrophylla) adalah salah satu jenis dari suku dipterocarpaceae. Secara geografis penyebaran jenis berada di Borneo yang secara ekologi tumbuh pada tanah latosol, podsolik merah kuning dan podsolik kuning pada tanah rendah yang tergenang selama musim hujan dan di tepi sungai sampai ketinggian $1.300 \mathrm{~m}$ dpl. Pohon Tengkawang buah memiliki kayu dengan kekuatan sedang, bisa mencapai ketinggian melebihi $50 \mathrm{~m}$ dengan banir mencapai $2 \mathrm{~m}$ dan diameter mencapai $>130 \mathrm{~cm}$. Sebagaimana jenis dari Shorea lainnya kegunaan kayu dari jenis ini adalah bangunan perumahan sebagai rangka, balok, galar, pintu, jendela, lantai dsb. Selain itu digunakan juga untuk pembuatan vinir dan kayu lapis. Adapun jenis ini memiliki berat jenis 0,40 $(0,29$ - 0,60) dan kelas kuat III - IV serta kelas awet III - V (Soerianegara dan Lemmens, 1994; Martawijaya et al., 1981).

\section{KEADAAN UMUM LOKASI PENELI- TIAN}

\section{a. Letak dan Luas}

Pengusahaan hutan alam produksi PT. Gunung Gajah Abadi berdasarkan SK Hak Pengusahaan Hutan No. 314/Kpts/Um/7/1973 tanggal 4 Juli 1973, semula dengan nama PT. Gunung Gajah. Perubahan nama berdasarkan Akte Notaris H. Bebasa DL, SH No. 129 tanggal 28 Januari 1982 serta Surat Keputusan Menteri Pertanian No. 833/Kpts/Um/1982 tanggal 28 Nopember 1982. Perpanjangan hak pengusahaan berdasarkan Surat Menteri Kehutanan No. 891/Menhut-IV/1994 tanggal 10 Juni 1994 yang kemudian ditetapkan dengan Surat Keputusan 
Menteri Kehutanan No. 261/Kpts-IV/1997 tanggal 19 Mei 1997 dengan luas areal hutan 81.000 ha.

Areal pengusahaan hutan terletak dalam kelompok hutan Sungai Seleq yang termasuk Bagian Kesatuan Pemangkuan Hutan (BKPH) Muara Wahau, CDK Mahakam Tengah. Batas persekutuan areal adalah sebagai berikut :

- Sebelah utara : HPH PT. Alas Helau

- Sebelah timur : HPH PT. Dharma Satya Nusantara dan PT Basuimex

- Sebelah selatan : HPH PT. Kayu Kalimantan

- Sebelah barat : HPH PT. Gunung Raya Utama Timber Ind.

Secara administrarif berada dalam wilayah Kecamatan Muara Wahau, Kabupaten Kutai Timur, Propinsi Kalimantan Timur.

\section{b. Kondisi Iklim}

Tipe iklim menurut Schmidt dan Ferguson (1951) di areal HPH PT. Gunung Gajah Abadi tergolong tipe A $(\mathrm{Q}=11,4 \%)$. Rata-rata curah hujan $2.580 \mathrm{~mm}$ per tahun, dengan curah hujan rata-rata bulanan tertinggi pada bulan Desember dan terendah pada bulan Agustus. Suhu udara berkisar antara $21^{\circ}-35^{\circ} \mathrm{C}$ dengan temperatur rata-rata $26^{\circ} \mathrm{C}$.

\section{c. Kondisi Tanah}

Dominansi jenis tanah yang ditemukan pada wilayah areal hutan terdiri atas empat jenis yaitu alluvial kelabu dan coklat, latosol dan podsolik. Tanah alluvial dicirikan dengan belum terbentuknya solum tanah, tekstur liat dan pasir kurang dari $50 \%$ struktur pejal dan warna tanah kelabu. Tanah podsol mempunyai solum yang dangkal, kurang dari $1 \mathrm{~m}$, peka terhadap erosi, warna tanah kelabu hingga kuning. Komplek podsol merupa- kan perpaduan antara podsolik merah kuning dengan latosol-litosol, solum agak tebal 1 - 2 m, tekstur beraneka ragam, strukturnya gumpal sampai pejal. Tanah latosol mempunyai solum yang sangat tipis kurang dari $50 \mathrm{~cm}$, teksturnya beraneka ragam, umumnya berpasir tanpa struktur. Jenis batuan dasar yang ditemukan adalah berupa batuan sedimen dengan bahan pengeras.

\section{d. Topografi}

Berdasarkan peta topografi dengan klasifikasi berdasarkan SK Mentan 837/Kpts/ Um/11/1980, maka areal hutan pengusahaan meliputi: kondisi landai (53\%), berbukit-bukit (9\%) dan bergelombang berat (38\%). Dengan keadaan lapangan berupa tanah kering seluas 90\% dan sisanya berupa hutan rawa (basah). Ketinggian areal hutan berada pada kisaran 100 $400 \mathrm{~m} \mathrm{dpl}$.

\section{e. Hidrologi}

Daerah Aliran Sungai (DAS) dan sub-DAS yang melintasi konsesi hutan mencakup beberapa sungai, yaitu Sungai Seleq, Sungai Jamtak dan Sungai Melgoan.

\section{f. Vegetasi dan Penutupan Lahan}

Dengan tipe hutan hujan tropika mempunyai komposisi jenis dominan dengan potensi yang cukup besar untuk jenis komersial, terutama dari suku dipterocarpaceae (lebih dari 65\%). Jenisjenis yang termasuk dalam kategori langka atau dilindungi masih ditemukan cukup besar pada areal hutan yaitu sebesar $8,63 \%$.

Kondisi penutupan lahan pada areal hutan berdasarkan peta penafsiran citra landsat tahun 2000 menunjukkan kondisi dan luasan areal sebagai berikut : 
- Hutan Produksi Terbatas :

- Hutan primer $($ virgin forest $)=$ seluas 25.601 ha

- Bekas tebangan (log over area) $=$ seluas 18.688 ha

- Hutan Produksi Tetap :

- Hutan primer $($ virgin forest $)=$ seluas 5.789 ha

- Bekas tebangan (log over area) $=$ seluas 22.817 ha

- Areal tidak berhutan

- Hutan Produksi Terbatas = seluas 2.711 ha

- Hutan Produksi Tetap = seluas 5.394 ha

g. Aksesibilitas

Untuk mencapai lokasi areal IUPHHK PT. GGA dapat ditempuh dengan transportasi darat Samarinda - Wahau selama \pm 10 jam.

\section{METODE PENELITIAN}

\section{A. Pengukuran Pohon Model}

Data pohon model dilakukan secara sengaja (purpossive sampling) untuk mendapatkan sebaran yang mewakili setiap kelas diameter dan dipilih yang memiliki pertumbuhan normal. Setiap pohon model diukur diameter pada ketinggian 1,3 $\mathrm{m}$ dari permukaan tanah atau 20 $\mathrm{cm}$ di atas banir. Tinggi pangkal tajuk dan diameter per seksi diukur dengan menggunakan alat spiegel relascope. Setiap pohon contoh dibagi menjadi beberapa seksi tergantung tingginya, adapun panjang setiap seksi adalah 2 $\mathrm{m}$, kecuali pada awal seksi dibuat $1 \mathrm{~m}$ dan ujung di bawah pangkal tajuk $<2 \mathrm{~m}$.

\section{B. Pengolahan Data}

Pengolahan data hasil pengukuran pohon model di lapangan meliputi :

\section{Pengukuran diameter}

Diameter perseksi diukur dengan rumus:

$\mathrm{D}=\mathrm{a} \times \mathrm{b} \times 2$

Dimana:

$\mathrm{D}=$ Diameter per seksi; $\mathrm{a}=$ Jarak datar; $\mathrm{b}=$ Jumlah relatif unit yang masuk pada Spiegel relascope

\section{Volume seksi per pohon}

Dasar perhitungan volume perseksi yang dipakai adalah berdasarkan rumus Smalian (Chapman dan Meyer, 1949) yaitu :

$$
\mathrm{V}_{\mathrm{i}}=\left[\left(\mathrm{G}_{\mathrm{pi}}+\mathrm{G}_{\mathrm{ui}}\right) / 2\right] \times \mathrm{P}_{\mathrm{i}}
$$

Dimana:

$\mathrm{V}_{\mathrm{i}}=$ Volume seksi ke $-\mathrm{i}\left(\mathrm{m}^{3}\right)$

$\mathrm{G}_{\mathrm{pi}}=$ Luas bidang dasar pangkal pada seksi-i

$\mathrm{G}_{\mathrm{ui}}=$ Luas bidang dasar ujung pada seksi-i

$\mathrm{P}_{\mathrm{i}} \quad=$ Panjang seksi-i

\section{Volume pohon model}

Volume pohon model diperoleh dari penjumlahan volume dari seksi-seksi yang membentuknya yang dihitung dengan cara :

$$
\mathrm{V}_{\text {pohon }}=\Sigma \mathrm{V}_{\mathrm{i}} \quad(\mathrm{i}=1,2,3 \ldots \mathrm{n})
$$

Dimana:

$$
\begin{aligned}
& \mathrm{V}_{\text {pohon }}=\text { Volume pohon }\left(\mathrm{m}^{3}\right) \\
& \mathrm{V}_{\mathrm{i}} \quad=\text { Volume seksi ke }-\mathrm{i} \\
& \mathrm{n} \quad=\text { Banyaknya seksi }
\end{aligned}
$$

\section{Penyusunan Model Pendugaan Volume Pohon}

Volume pohon diperoleh dari penjumlahan volume per seksi pada pohon yang bersangkutan. 
Volume pohon kemudian dihubungkan dengan peubah bebas untuk mendapatkan persamaan volume. Metode pendugaan volume lokal ini berdasarkan satu peubah saja yaitu diameter.

Jumlah pohon untuk penyusunan tabel volume ini berkisar antara 25-30 pohon dengan memperhatikan sebaran diameter (Chapman dan Meyer, 1949).

Dalam penelitian ini bentuk persamaan regresi yang disusun disajikan pada Tabel 1 .

\section{Validasi Persamaan Terpilih}

Loetsch dan Haller (1973) menyatakan bahwa tabel volume lokal dibatasi oleh pemakaiannya yaitu terbatas pada jenis atau kelompok dan kondisi tapak yang sama. Sedangkan menurut Spurr (1951) dan Husch
(1963) bahwa model pendugaan volume pohon yang baik adalah persamaan yang mempunyai nilai simpangan agregatif kurang dari $1 \%$ dan simpangan rataan kurang dari 10\%.

\section{HASIL DAN PEMBAHASAN}

\section{A. Pengukuran Pohon Model}

Jumlah pohon model yang dipakai sebagai obyek penelitian sebanyak 51 pohon diambil yang dipilih secara purposif dengan maksud untuk memenuhi kelas diameter didalam pembuatan regresi. Pohon model tersebut memiliki kisaran antara $10-80 \mathrm{~cm}$ yang menyebar pada setiap kelas diameter dengan interval $10 \mathrm{~cm}$. Secara grafis, sebaran diameter dari pohon model digambarkan pada Gambar 1.

Iabel (lable) 1. Persamaan regresı menduga volume pohon berdasarkan diameter setıngg1 dada.

(Regression equation to predict wood volume based on diameter at breast height)

\begin{tabular}{|c|c|c|c|}
\hline $\begin{array}{c}\text { No } \\
(\text { Number) }\end{array}$ & $\begin{array}{c}\text { Peubah Bebas } \\
\text { (Variable of Freedom) }\end{array}$ & $\begin{array}{c}\text { Dikembangkan oleh } \\
\text { (developed by) }\end{array}$ & Model rumus (formula model) \\
\hline 1 & Diameter $(\mathrm{d})$ & Kopazky - Gehrhardt & $\mathrm{V}=\mathrm{b} 0+\mathrm{b}_{1} \mathrm{~d}^{2}$ \\
\hline 2 & Diameter (d) & Hohendl - Krenn & $\mathrm{V}=\mathrm{b}_{0}+\mathrm{b}_{1} \mathrm{~d}+\mathrm{b}_{2} \mathrm{~d}^{2}$ \\
\hline 3 & Diameter (d) & Husch & $\log V=b_{0}+b_{1} \log d$ \\
\hline 4 & Diameter (d) & Bren ac & $\log V=b_{0}+b_{1} \log d+b_{2}(1 / d)$ \\
\hline 5 & Diameter $(d)$ & Bustomi et al. (1998) & $\mathrm{V}=\mathrm{a}+\mathrm{b} \log \mathrm{d}$ \\
\hline
\end{tabular}

Sumber (source) : Nomor 1 s/d 4 dari Loetsch dan Haller (1973)

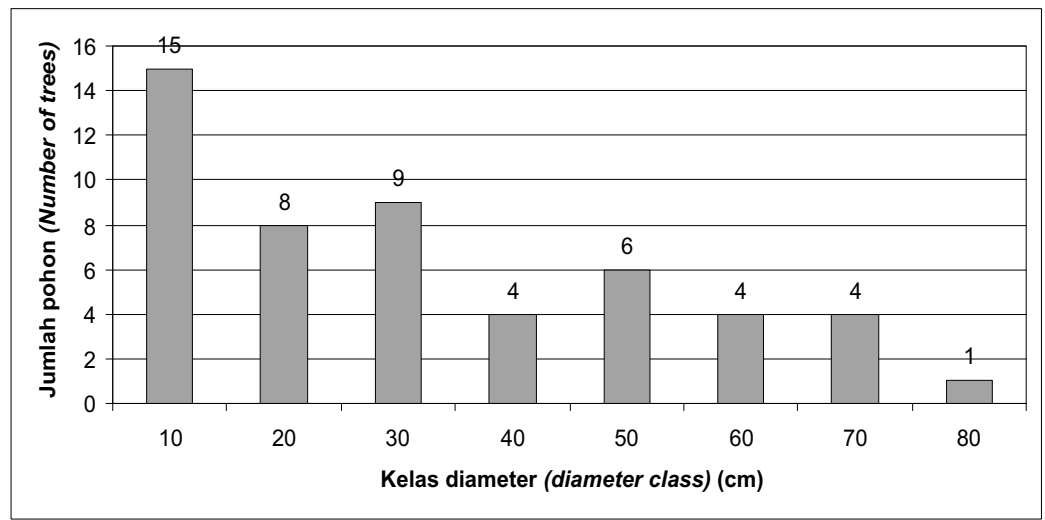

Gambar (Figure) 1. Sebaran kelas diameter pohon model Shorea macrophylla (Distribution of diameter class of Shorea macrophylla sample trees). 
Tabel (Table) 2. Persamaan regresi hubungan antara diameter dan tinggi bebas cabang untuk jenis Shorea macrophylla (Regression equation of relationship between diameter dan heigh of crown base of Shorea macrophylla)

\begin{tabular}{|c|c|c|c|c|c|}
\hline $\begin{array}{c}\text { No } \\
\text { (Number) }\end{array}$ & Jenis (species) & Persamaan (Equation) & $\begin{array}{c}\text { Koefisien } \\
\text { Korelasi (Coef. } \\
\text { Correlation) }\end{array}$ & $\begin{array}{c}\text { Koefisien } \\
\text { Determinasi (Coef. } \\
\text { Determination) }\end{array}$ & $\begin{array}{c}\text { Kesalahan } \\
\text { baku (Standard } \\
\text { Error) }\end{array}$ \\
\hline 1. & $\begin{array}{l}\text { Shorea } \\
\text { macrophylla }\end{array}$ & $\begin{array}{l}\mathrm{T}=4,887+0,451 \mathrm{D} \\
-0,0038 \mathrm{D}^{2}\end{array}$ & 0,7867 & 0,6190 & 2,6858 \\
\hline
\end{tabular}

\section{B. Hubungan Diameter dan Tinggi}

Pengujian terhadap hubungan antara diameter dan tinggi diperlukan untuk pembuatan model pendugaan volume. Hal ini penting karena menyangkut persamaan yang akan dibuat dengan berdasarkan diameter saja atau keduanya. Persamaan hanya berdasarkan diameter (tarif) dapat dilakukan jika dalam pengujian terdapat hubungan yang erat diameter dan tinggi.

Rekapitulasi hasil perhitungan dengan mencobakan hubungan antara diameter dan tinggi dapat terlihat pada Tabel 2.

Hasil perhitungan koefisien korelasi (r) memiliki nilai yang besar. Hal ini dapat dibandingkan dengan nilai yang tertera tabel taraf signifikansi 0,01 sebesar 0,351 (Snedecor dan Cochran, 1967). Dengan demikian terdapat hubungan yang signifikan yang dinyatakan dengan $r$ hitung $>$ r tabel.
Berdasarkan hal tersebut penyusuanan persamaan volume dapat dengan menggunakan satu variabel saja yaitu diameter (Tarif).

Kurva hubungan regresi diameter dan tinggi dapat dilihat pada Gambar 2.

Dari Gambar 2 dilakukan analisis kurva tinggi. Hasil analisis kurva tinggi untuk jenis ini ditunjukkan dalam Tabel Analisis Varians (Anova) seperti disajikan pada Tabel 3.

Besarnya nilai F-hitung dari F-tabel menunjukkan ada perbedaan yang signifikan terhadap persamaan yang dibuat, sehingga ada kerterkaitan antara variabel yang dicobakan yaitu diameter dan tinggi.

\section{Penyusunan Persamaan Volume}

Analisis persamaan regresi dari lima persamaan yang dibuat dalam penyusunan tabel volume lokal (tarif) dari dari jenis Shorea macrophylla disajikan pada Tabel 4.

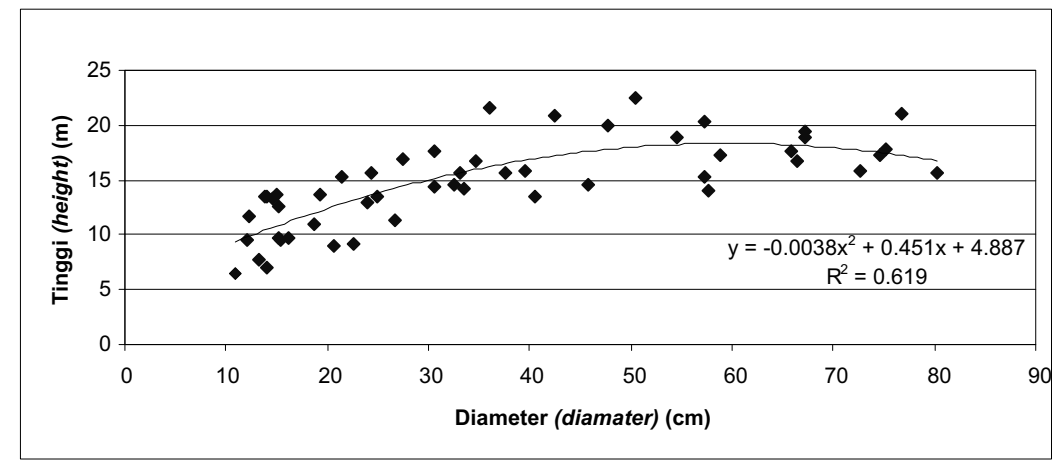

Gambar (Figure) 2. Kurva hubungan diameter dan tinggi pohon model (Curve of relationship between diameter and high of crown base of sample trees) 
Tabel (Table) 3. Analisis varian (ANOVA) variabel diameter dan tinggi dari Shorea macrophylla (Analysis of Varians of diameter and height of Shorea macrophylla).

\begin{tabular}{|c|c|c|c|c|c|}
\hline $\begin{array}{l}\text { Sumber Keragaman } \\
\text { (Source of Variation) }\end{array}$ & $\begin{array}{c}\text { Derajat bebas } \\
\text { (Degree of Freedom) }\end{array}$ & $\begin{array}{l}\text { Jumlah kuadrat } \\
\text { (Sum of Square) }\end{array}$ & $\begin{array}{l}\text { Rataan kuadrat } \\
\text { (Mean of Square) }\end{array}$ & $\begin{array}{l}\text { Fhit } \\
(F v a l)\end{array}$ & $F_{t a b 99 \%}$ \\
\hline $\begin{array}{l}\text { Regresi } \\
\text { (Regression) }\end{array}$ & 2 & 442.1269 & 221.0635 & 30.64 & 3.21 \\
\hline $\begin{array}{l}\text { Sisa } \\
\text { (Residual) }\end{array}$ & 51 & 367.8946 & 7.213619 & & \\
\hline Jumlah(Total) & 53 & 810.0215 & & & \\
\hline
\end{tabular}

ıabeı ( Iabıe) 4. Hasıl pengolanan beberapa persamaan regres1 yang aluj1 untuk jenis snorea macrophylla (The result preparation test several Regression equation of Shorea macrophylla)

\begin{tabular}{ccccc}
$\begin{array}{c}\text { No } \\
(\text { Number })\end{array}$ & Persamaan (Equations) & $\begin{array}{c}\text { Koefisien } \\
\text { Korelasi (Coef. } \\
\text { Correlation) }\end{array}$ & $\begin{array}{c}\text { Koefisien } \\
\text { Determinasi (Coef. } \\
\text { Determination) }\end{array}$ & $\begin{array}{c}\text { Kesalahan } \\
\text { baku (Standard } \\
\text { Error) }\end{array}$ \\
\hline 1 & $\mathrm{~V}=-0.2156+0.0011 \mathrm{~d}^{2}$ & 0.9736 & 0.9479 & 0.4617 \\
\hline 2 & $\mathrm{~V}=0.0771-0.0176 \mathrm{~d}+0.0013 \mathrm{~d}^{2}$ & 0.9743 & 0.9493 & 0.4601 \\
\hline 3 & $\log \mathrm{V}=-3.9963+2.5535 \log \mathrm{d}$ & 0.9857 & 0.9716 & 0.1170 \\
\hline 4 & $\log \mathrm{V}=-3.3545+2.2249 \log \mathrm{d}-3.9328(1 / \mathrm{d})$ & 0.9862 & 0.9727 & 0.1162 \\
\hline 5 & $\mathrm{~V}=-8.0407+6.5209 \log \mathrm{d}$ & 0.8653 & 0.7488 & 1.0139 \\
\hline
\end{tabular}

Dari hasil analisis tersebut terlihat nilai $\mathrm{r}$ yang besar, selanjutnya nilai ini dapat diuji dengan melihat besarnya r-tabel pada taraf signifikansi 0,01 memiliki nilai 0,351 (Snedecor dan Cochran, 1967). Nilai $r$ hitung $>r$ tabel sehingga diantara keduanya peubah tersebut terdapat hubungan yang signifikan.

Perhitungan analisis variasi dari persamaan ini ditunjukkan dalam Tabel Analisis Varians (Anova) seperti disajikan pada Tabel 5.

Besarnya nilai F-hitung dari F-tabel pada Tabel 5 menunjukkan ada perbedaan yang signifikan terhadap persamaan yang dibuat, sehingga ada keterkaitan antara variabel yang dicobakan yaitu diameter dan volume.

Berdasarkan nilai koefisien determinasi dan nilai standar eror serta nilai F-hitung dari persamaan yang terbentuk hasil analisis regresi yang dilakukan, maka persamaan regresi yang terpilih untuk jenis ini adalah persamaan regresi Nomor 4.

\section{Validasi Model}

Kriteria uji lain pada tahapan selanjutnya setelah persamaan regresi terpilih yang akan diaplikasi- kan perlu dilakukan validasi model. Validasi model dilakukan dengan menghitung nilai simpangan agregatif ( $\mathrm{Sa}$ ) dan simpangan rataan (Sr) dari nilai volume aktual dan volume taksiran hasil persamaan regresi terpilih dan nilai standar error yang terbentuk. Hasil perhitungan nilai simpangan agregatif (SA) adalah -1,54 dan simpangan rataan (SR) adalah 3,26. 
Tabel (Table) 5. Analisis varian (ANOVA) variabel volume dan diameter dari Shorea macrophylla (Analysis of varians of volume and diameter of Shorea macrophylla).

\begin{tabular}{|c|c|c|c|c|c|}
\hline $\begin{array}{l}\text { Sumber Keragaman } \\
\text { (Source of Variation) }\end{array}$ & $\begin{array}{c}\text { Derajat Bebas } \\
\text { (Degree of Freedom) }\end{array}$ & $\begin{array}{l}\text { Jumlah Kuadrat } \\
\text { (Sum of Square) }\end{array}$ & $\begin{array}{l}\text { Rataan kuadrat } \\
\text { (Mean of Square) }\end{array}$ & $\begin{array}{l}\text { Fhit } \\
(F v a l)\end{array}$ & $\boldsymbol{F}_{t a b 99 \%}$ \\
\hline $\begin{array}{l}\text { Regresi } \\
\text { (Regression) }\end{array}$ & 2 & 23.0597 & 11.5298 & 854.28 & 3.21 \\
\hline $\begin{array}{l}\text { Sisa } \\
\text { (Residual) }\end{array}$ & 48 & 0.6478 & 0.0134 & & \\
\hline Jumlah (Total) & 50 & 23.7075 & & & \\
\hline
\end{tabular}

Dari hasil tersebut di atas menunjukkan bahwa model persamaan regresi pendugaan volume terpilih dapat dilanjutkan penyusunan tabel volume pohon. Penentuan kriteria ini berdasarkan standar menurut Spurr (1951) dan Husch (1963) yang menyatakan bahwa model pendugaan volume pohon yang baik adalah persamaan yang mempunyai nilai simpangan agregatif kurang dari $1 \%$ dan simpangan rataan kurang dari $10 \%$.

\section{KESIMPULAN DAN SARAN}

\section{A. Kesimpulan}

Berdasarkan hasil penelitian ini model persamaan terpilih untuk jenis pohon tengkawang (Shorea macrophylla) adalah persamaan regresi berdasarkan peubah bebas diameter yang memiliki tingkat ketelitian tertinggi yaitu persamaan:

$\log V=-3,3545+2,2249 \log d-3,9328(1 / d)$.

\section{B. Saran}

Penggunaan persamaan volume ini bersifat lokal yakni hanya pada daerah penelitian saja karena penggunaan secara umum akan memberikan hasil yang berbeda yang disebabkan oleh perbedaan tapak.

\section{DAFTAR PUSTAKA}

Akinnifesi, A.K. 1995. Linear equation for estimation the marchantable wood volume of Gmelina arborea IN South West Nigeria. Journal of Tropical Science 7(3). 391-397.

Bambang E.D. dan D. Wahyono. 1996. Tabel isi pohon jenis rasamala (Altingia exelsa) di KPH Cianjur, Jawa Barat. Buletin Penelitian Hutan. Bogor

Bustomi, S., Harbagung, D. Wahyono dan I.B.P. Parthama. 1998. Petunjuk teknis tata cara penyusunan tabel volume pohon. Badan Penelitian dan Pengembangan Kehutanan. Pusat Penelitian dan Pengembangan hutan Konservasi Alam. Info Hutan Bogor.

Chapman, H.H and W.H Meyer 1949. Forest Mensuration. Mc. Graw Hill Book Company Inc. New York.

Husch, B. 1963. Forest Mensuration and Statistics. Ronald Press Company Inc. New York.

Loetsch, F and Haller, K. 1973. Forest Inventory Volume II. BLV Verlagsgesellschaft, Munchen.

Martawijaya A, I. Kartasujana, K. Kadir, S.A. Prawira. 1981. Atlas Kayu Indonesia jilid I. Balai Penelitian Hasil Hutan. Badan 
Penelitian dan Pengembangan Pertanian.

Bogor

Schmidt, F. H. and J. H. A. Ferguson. 1951.

Rainfall Type Based on Wet and Dry Period

Ratios for Indonesia with Western New

Guinea. Verhand 42. Direktorat Meteorologi dan Geofisika. Jakarta.

Soerianegara, I. and R.H.M.J Lemmens (Editors). 1994. Timber trees: Major commercial timber. Plant Resources of South - east Asia (PROSEA) No. 5 (1). Bogor.

Steel, R.G.D. and H. Torrie. 1960. Principles and Procedures of Statistics. McGraw - Hill book Company, Inc.

Spurr, S.H. 1951. Forest Inventory. The Ronald Press Co. New York. 